\title{
Selection of Health Care Workers for Screening for Latent Tuberculosis Infection
}

\author{
Jin Young Lee', Ji Young Park2², Myung Shin Kim³ , Je Hun Kim¹, Jin-Young Lee ${ }^{4}$ \\ ${ }^{1}$ Department of Internal Medicine, Kosin University College of Medicine, Busan, Republic of Korea \\ ${ }^{2}$ Department of Internal Medicine, Kosin University Gospel Hospital, Busan, Republic of Korea \\ ${ }^{3}$ Department of Internal Medicine, Soonchunhyang University College of Medicine, Gumi Hospital, Gumi, Republic of Korea \\ ${ }^{4}$ Department of Infection Control, Kosin University Gospel Hospital, Busan, Republic of Korea \\ Email: rejim@hanmail.net, *aiteite1@naver.com, g72264@schmc.ac.kr, libertier@gmail.com, dearjin0@hanmail.net
}

How to cite this paper: Lee, J.Y., Park, J.Y., Kim, M.S., Kim, J.H. and Lee, J.-Y. (2019) Selection of Health Care Workers for Screening for Latent Tuberculosis Infection. Journal of Tuberculosis Research, 7, 65-76.

https://doi.org/10.4236/jtr.2019.72007

Received: April 25, 2019

Accepted: June 16, 2019

Published: June 19, 2019

Copyright () 2019 by author(s) and Scientific Research Publishing Inc. This work is licensed under the Creative Commons Attribution International License (CC BY 4.0).

http://creativecommons.org/licenses/by/4.0/

\begin{abstract}
Introduction: The rate of latent tuberculosis infections (LTBIs) in health care workers (HCWs) is higher than that in non-HCWs. We studied to investigate the prevalence and risk factors of LTBIs and the acceptance rate for treatment of LTBI among HCWs in South Korea, a country with an intermediate tuberculosis (TB) burden. Methodology: LTBI screening was conducted for HCWs at a tertiary and a secondary hospital from April 2017 to August 2017. This was a retrospective study included all HCWs who underwent LTBI examination. HCWs were classified by the degree of risk into four groups, based on two factors: possibility of exposure to $\mathrm{TB}$, and impact on patients at the time of TB onset in the HCWs. The interferon-gamma release assay was used for the diagnosis of LTBI. Results: A total of 1326 HCWs were included; they comprised 801 HCWs from a tertiary hospital and 525 from a secondary hospital. A total of 235 (17.7\%) HCWs were diagnosed with LTBIs. According to risk classification, there was no significant difference $(P=0.24)$. In multivariate analysis, age was the only independent risk factor $(P<0.001)$. The acceptance rate for LTBI treatment was $60.43 \%$, and there were no associated factors in multivariate analysis. Conclusions: HCWs did not show any significant difference in the rate of LTBI by the degree of risk, and age was the independent risk factor. LTBI screening should be conducted for all HCWs regardless of risk classification.
\end{abstract}

\section{Keywords}

Health Care Workers, Latent Tuberculosis, Prevalence, Treatment

\section{Introduction}

The World Health Organization (WHO) announced that tuberculosis (TB) was 
a global public health emergency in 1993. About 10 million new TB cases are diagnosed annually worldwide, making the incidence of TB 140 per 100,000 population [1].

The incidence of TB in South Korea, a country with an intermediate TB burden, was 77 per 100,000 population in 2016, which is somewhat lower than the worldwide average, but is the highest among the members of the Organization for Economic Cooperation and Development [2].

About one-third of the world's population, i.e., approximately 2 billion people, are considered to be infected with latent TB; these latent TB infections (LTBIs) do not cause symptoms and are not contagious, but they may progress to active disease and become infectious [3]. LTBI occurs in 30\% of those in close contact with $\mathrm{TB}$ patients, and approximately $5 \%$ to $10 \%$ develop active $\mathrm{TB}$ throughout their lifetimes [4]. The risk of progression can be decreased by $\sim 90 \%$ through treatment of LTBI [4] [5]. Therefore, the early diagnosis and treatment of LTBI can help to decrease the long-term burden of TB [6]. HCWs are at a high risk of being exposed to active TB patients who have not been detected; thus, their risk of TB infection is high, i.e., reportedly about 3.2 times higher than that of the general population [7] [8] [9]. Furthermore, when HCWs develop active TB, they may transmit the infection to their patients, including immunocompromised individuals [10]. The Centers for Disease Control and Prevention (CDC) published guidelines for preventing the spread of Mycobacterium tuberculosis (MTB) in healthcare facilities and recommended TB screening programs for all HCWs, with the provision of treatment when LTBI is diagnosed [11] [12]. Although the tuberculin skin test (TST) has been widely used for the diagnosis of LTBI, there is a limitation in that the TST may detect cross reactions with nontuberculous mycobacterial strains or with $M$. bovis vaccine strains, and the probability of false-positive results is high. The CDC recommends interferongamma release assay (IGRA) as a better alternative to TST for LTBI detection [13] [14]. To address the issue of LTBI screening in the HCW population in Korea, the Korean Manual for TB Management in Medical institutions was updated in 2016 [15]. Based on these guidelines, we studied the prevalence and risk factors for LTBI and the acceptance rate for LTBI treatment among HCWs in a tertiary and a secondary hospital.

\section{Methodology}

\subsection{Study Population}

This was a retrospective review of medical records of all HCWs being tested for LTBI. LTBI screening in HCWs was conducted from April 2017 to August 2017 at a tertiary hospital (hospital A) with 969 beds and a secondary hospital (hospital B) with 450 beds in South Korea based on the guideline. The HCWs included all employees (e.g., physicians, nurses, nursing assistants, paramedics, clerical staff, laboratory workers, food service workers) working in the hospital. After being advised to undergo LTBI examination through official communica- 
tion by a section chief, HCWs decided to undergo the examination or not voluntarily. All HCWs who underwent the LTBI examination were enrolled in this study. According to the Manual for TB Management in Medical Institutions, HCWs were classified by the degree of risk into four groups based on two factors: possibility of exposure to MTB; and impact on patients at the time of TB onset in the HCWs (Table 1).

We excluded HCWs who either completed treatment of TB or LTBI in the past or were currently being treated. But there was no baseline data of LTBI for all staff. We obtained information regarding working healthcare facility, age, sex, number of years of service, department of work (doctors, nurses, nursing assiatants, lab workers, and others including clerks) for all participants via analyzing the medical records. To rule out active TB while screening for LTBI, all participants underwent a chest X-ray examination.

\subsection{LTBI Screening}

LTBI testing was performed with the IGRA test using the QuantiFERON-TB Gold in-Tube blood test (QFT-GIT; Cellestis Ltd., Carnegie, VIC, Australia). The cost of the examination for LTBI was reimbursed as per national policy. The QFT-GIT assay was performed according to the manufacturer's instructions. Briefly, whole blood is drawn into 3 evacuated blood collection tubes: one containing heparin alone (negative control), one containing $\mathrm{T}$ cell mitogen (positive

Table 1. Classification of latent tuberculosis infection risk in health care workers according to the Korean Manual for Tuberculosis Management in Medical institutions.

\begin{tabular}{|c|c|c|c|}
\hline & Category & Definition & Department \\
\hline Group 1 & $\begin{array}{l}\text { High probability of contact } \\
\text { with patients with respiratory } \\
\text { TB }\end{array}$ & $\begin{array}{l}\text { HCWs constantly care for } \\
\text { patients with respiratory } \\
\text { TB }\end{array}$ & $\begin{array}{l}\text { - Pulmonology } \\
\text { - Infectious diseases } \\
\text { - Medical ICU } \\
\text { - Emergency department } \\
\text { - Bronchoscopy unit } \\
\text { - Spirometry unit } \\
\text { - TB-related laboratory }\end{array}$ \\
\hline Group 2 & $\begin{array}{l}\text { High probability of contact } \\
\text { with patients with a high risk } \\
\text { of disseminated disease if } \\
\text { infected with TB }\end{array}$ & $\begin{array}{l}\text { HCWs care for } \\
\text { immunocompromised } \\
\text { patients, who are at a high } \\
\text { risk of a severe form of } \mathrm{TB} \\
\text { if infected }\end{array}$ & $\begin{array}{l}\text { - Hemato-oncology } \\
\text { - Gynecology } \\
\text { - Neonatal care unit } \\
\text { - } \cdot \text { Hemodialysis unit }\end{array}$ \\
\hline Group 3 & $\begin{array}{l}\text { Relatively low probability of } \\
\text { contact with patients with } \\
\text { respiratory TB }\end{array}$ & $\begin{array}{l}\text { Other HCWs who care for } \\
\text { patients and who may } \\
\text { come into contact with } \\
\text { patients with respiratory } \\
\text { TB }\end{array}$ & $\begin{array}{l}\text { - Other clinical departments, } \\
\text { - not categorized as group } 1 \\
\text { or } 2 \\
\text { - Primary healthcare center }\end{array}$ \\
\hline Group 4 & $\begin{array}{l}\text { Low probability of risk of TB } \\
\text { infection }\end{array}$ & $\begin{array}{l}\text { Other HCWs, not } \\
\text { mentioned above, with a } \\
\text { low probability of contact } \\
\text { with patients with } \\
\text { respiratory TB }\end{array}$ & - Office clerks \\
\hline
\end{tabular}

TB: Tuberculosis; ICU: Intensive Care Unit; HCW: health care worker. 
control), and one containing $M$. tuberculosis-specific antigens, including early secreted antigenic target 6 , culture filtrate protein 10, and TB7.7 (TB-antigen tube). Following 16 - 24 hours of incubation, the concentration of interferon-gamma (IFN- $\gamma$ ) was determined by enzyme-linked immunosorbent assay. The QFT-GIT test result is considered positive if the IFN- $\gamma$ response level is at least $0.35 \mathrm{IU} / \mathrm{ml}$.

\subsection{LTBI Treatment and Monitoring during Treatment}

HCWs with positive results in the LTBI screening test visited outpatient clinics, and had their medical records reviewed by internal medicine doctors. After receiving explanation in outpatient clinics about LTBI, including the criteria for diagnosis, risks, and benefits of treatment, each HCWs were given the options of treatment. Four treatment options were offered: isoniazid (INH) $300 \mathrm{mg}$ orally/rifampin (RIF) $600 \mathrm{mg}$ (450 mg if body weight was $<50 \mathrm{~kg}$ ) orally daily for 3 months; RIF $600 \mathrm{mg}$ ( $450 \mathrm{mg}$ if body weight was $<50 \mathrm{~kg}$ ) orally daily for 4 months; INH $300 \mathrm{mg}$ orally daily for 9 months; and no treatment. The INH/RIF regimen was recommended as the preferred option. According to the guidelines of the National Institutes for Health and Clinical Excellence (NICE), the regimen had the highest compliance rate in a short period, and treatment results were better than those of other regimens. Treatment costs and related examination expenses were covered by the government. Basal complete blood count, aspartate aminotransferase/alanine aminotransferase, bilirubin, blood urea nitrogen and creatinine were measured prior to treatment. Follow-up examinations were performed at 2, 4, 8 and 12 weeks after the start of treatment. HCWs visited outpatient clinics and were examined for side effects, such as skin disease and so on.

\subsection{Statistical Analysis}

Comparisons between groups were made using the $\mathrm{x}^{2}$ test for categorical variables and the Student's t-test for continuous variables. Independent variables were analyzed using the logistic regression analysis, and a $P$-value of $<0.05$ was considered statistically significant. All statistical analyses were performed using SPSS version 23.0 (IBM Corp., Armonk, NY, USA).

\subsection{Ethics Statement}

The study was approved by the Institutional Review Board of each participating institution.

\section{Results}

\subsection{Characteristics of Study Subjects}

In this study, 45.2\% (810/1790) of HCWs at hospital A and 74.4\% (526/707) of HCWs at hospital B underwent the LTBI examination. Among them, $10 \mathrm{HCWs}$ who had been previously treated with active TB or LTBI were excluded. A total of $1326 \mathrm{HCWs}$ were included in the study, with an average age of $40.99 \pm 10.86$ 
years. The clinical characteristics are followed by Table 2. Of the total, 801 HCWs (60.4\%) worked at hospital A and 525 HCWs (39.6\%) worked at hospital B. The average age of the HCWs at hospital A was $41.29 \pm 11.25$ years, and at hospital B was $40.47 \pm 10.21$ years, with no significant difference $(P=0.577)$. The most populous age group when divided into ten-year intervals was that with individuals 20 - 29 years of age, with 606 HCWs (45.7\%). The proportion of

Table 2. Clinical characteristics of 1326 health care workers.

\begin{tabular}{|c|c|}
\hline Characteristics & Total (\%) \\
\hline \multicolumn{2}{|l|}{ Heath care facility } \\
\hline tertiary hospital (hospital A) & $801(60.4)$ \\
\hline secondary hospital (hospital B) & $525(39.6)$ \\
\hline \multicolumn{2}{|l|}{ Age range, years } \\
\hline $20-29$ & $606(45.7)$ \\
\hline $30-39$ & $362(27.3)$ \\
\hline $40-49$ & $219(16.5)$ \\
\hline$\geq 50$ & $139(10.5)$ \\
\hline \multicolumn{2}{|l|}{ Gender } \\
\hline Female & $980(73.9)$ \\
\hline Male & $346(26.1)$ \\
\hline \multicolumn{2}{|l|}{ Years working in hospital } \\
\hline$<11$ & $908(68.5)$ \\
\hline $11-20$ & $174(13.1)$ \\
\hline $21-30$ & $179(13.5)$ \\
\hline$>30$ & $65(4.9)$ \\
\hline \multicolumn{2}{|l|}{ Latent tuberculosis infection } \\
\hline No & $1091(82.3)$ \\
\hline Yes & $235(17.7)$ \\
\hline \multicolumn{2}{|l|}{ Profession } \\
\hline Doctors & $189(14.3)$ \\
\hline Nurses & $801(60.4)$ \\
\hline Nursing assistants, paramedics & $130(9.8)$ \\
\hline Lab workers & $55(4.1)$ \\
\hline Others, including clerks & $151(11.4)$ \\
\hline \multicolumn{2}{|l|}{ Risk classification } \\
\hline Group 1 & $300(22.6)$ \\
\hline Group 2 & $233(17.6)$ \\
\hline Group 3 & $633(47.7)$ \\
\hline Group 4 & $160(12.1)$ \\
\hline
\end{tabular}


HCWs who had worked less than 11 years was highest, at 68.5\% (908). In terms of the classification of HCWs according to the degree of risk, the most populous was group 3, with $633 \mathrm{HCWs}(47.7 \%)$. Nurses were the largest occupational category, with 801 members (60.4\%).

\subsection{Risk Factors for LTBI}

The risk factors for LTBIs are followed by Table 3. Of the 1326 HCWs, 235 (17.7\%) were diagnosed with LTBI. The rate of HCWs diagnosed with LTBI at hospital A

Table 3. Risk factors for latent tuberculosis infection among $1326 \mathrm{HCWs.}$

\begin{tabular}{|c|c|c|c|c|c|}
\hline Variables & $\begin{array}{c}\text { Total } \\
\mathrm{N}=1326\end{array}$ & LTBI (\%) & $P$-value & $\begin{array}{l}\text { Multivariate analysis } \\
\text { Odds ratio }(95 \% \mathrm{CI})\end{array}$ & $P$-value \\
\hline \multicolumn{6}{|l|}{ Heath care facility } \\
\hline tertiary hospital (hospital A) & 801 & $149(18.6)$ & 0.30 & & \\
\hline secondary hospital (hospital B) & 525 & $86(16.4)$ & & & \\
\hline \multicolumn{6}{|l|}{ Age range, years } \\
\hline $20-29$ & 606 & $47(7.8)$ & $<0.001$ & Reference & \\
\hline $30-39$ & 362 & $57(15.7)$ & & $2.22(1.47-3.35)$ & $<0.001$ \\
\hline $40-49$ & 219 & $69(31.5)$ & & $5.47(3.62-8.26)$ & $<0.001$ \\
\hline$\geq 50$ & 139 & $62(44.6)$ & & $9.58(6.12-14.99)$ & $<0.001$ \\
\hline \multicolumn{6}{|l|}{ Sex } \\
\hline Female & 980 & $150(15.3)$ & $<0.001$ & & \\
\hline Male & 346 & $85(24.6)$ & & $1.19(0.80-1.77)$ & 0.40 \\
\hline \multicolumn{6}{|l|}{ Years working in hospitals } \\
\hline$<11$ & 908 & $102(11.2)$ & $<0.001$ & Reference & \\
\hline $11-20$ & 174 & $40(23.0)$ & & $1.37(0.85-2.23)$ & 0.20 \\
\hline $21-30$ & 179 & $61(34.1)$ & & $1.27(0.71-2.26)$ & 0.43 \\
\hline$>30$ & 65 & $32(49.2)$ & & $1.88(0.82-4.31)$ & 0.14 \\
\hline \multicolumn{6}{|l|}{ Profession } \\
\hline Doctors & 189 & $41(21.7)$ & $<0.001$ & Reference & \\
\hline Nurses & 801 & $110(13.7)$ & & $0.75(0.45-1.25)$ & 0.30 \\
\hline Nursing assistants, Paramedics & 130 & $34(26.2)$ & & $0.93(0.52-1.65)$ & 0.81 \\
\hline Lab workers & 55 & $15(27.3)$ & & $0.98(0.46-2.10)$ & 0.96 \\
\hline Others, including clerks & 151 & $35(23.2)$ & & $0.79(0.44-1.41)$ & 0.42 \\
\hline \multicolumn{6}{|l|}{ Risk classification } \\
\hline Group 1 & 300 & $51(17.0)$ & 0.24 & & \\
\hline Group 2 & 233 & $43(18.5)$ & & & \\
\hline Group 3 & 633 & $104(16.4)$ & & & \\
\hline Group 4 & 160 & $37(23.1)$ & & & \\
\hline
\end{tabular}

LTBI: latent tuberculosis infection. 
was $18.6 \%(149 / 801)$ and at hospital B was $16.4 \%(86 / 525)(P=0.30)$. The average age of HCWs diagnosed with LTBI was $32.32 \pm 9.30$ years and that of non LTBI HCWs was $40.99 \pm 10.86$ years $(P<0.001)$. Of the HCWs diagnosed with LTBI, $44.6 \%(62 / 139)$ were 50 years or older, and the higher the age, the higher was the LTBI rate $(P<0.001)$. Of those with more than 30 years of work in the hospitals, 32 (49.2\%) were positive, with the LTBI rate increasing with the number of years of medical service $(P<0.001)$. The rate of LTBI was higher in males, with 85 cases $(24.6 \%)(P<0.001)$. According to the occupational classification, the LTBI rate was significantly higher in lab workers, with 15 cases $(27.3 \%)$, compared with doctors and nurses $(P<0.001)$. According to the classification by the degree of risk, there were no significant differences $(P=0.24)$. In multivariate analysis, only age was independently associated with increased risk for LTBI $(P<0.001)$.

\subsection{Treatment of LTBI}

Of the 235 HCWs diagnosed with LTBI, 142 (60.4\%) started treatment for LTBI. The determinants associated with acceptance rate for LTBI treatment are shown in Table 4. The acceptance rate of HCWs at hospital B was 70.9\% (61/86), higher than that at hospital A $(54.4 \%, 81 / 149)(P=0.01)$. In terms of age, the acceptance rate of the 20-29 years group was the highest $(P<0.001)$. The acceptance rate was $66.0 \%(99 / 150)$ in females and $50.6 \%(43 / 85)$ in males $(P=0.02)$. In terms of years of work in the hospitals, the acceptance rate was the highest in those with less than 11 years of work, at $70.6 \%(P=0.02)$. In terms of the classification according to the degree of risk, the acceptance rate was the highest in group 1 with $68.6 \%(P=0.04)$. In multivariate analysis, there were no independently associated factors.

Of the $142 \mathrm{HCW}$ who started LTBI treatment, 125 (88.7\%) chose INH/RIF, 9 (6.4\%) chose RIF and 7 (5\%) chose INH. Overall, 9 of 142 (6.3\%) HCWs who started treatment with INH/RIF interrupted the treatment due to adverse effects. Four HCWs interrupted it with hepatotoxicity, 3 HCWs with dizziness, and 2 HCWs with skin rash. HCWs diagnosed as LTBI have been screened annually with chest X-rays to confirm whether LTBI transit to active tuberculosis.

\section{Discussion}

In this study, we identified the prevalence and risk factors of LTBI among HCWs in South Korea, a country with an intermediate TB burden, and investigated the treatment acceptance rate of HCWs with LTBI. The proportion of HCWs diagnosed with LTBI was $17.7 \%$, consistent with the prevalence reported by several studies on LTBI among HCWs in South Korea [16]. According to research in South Korea published in 2010, the prevalence of LTBI in HCWs in a university hospital was $23.2 \%$, as measured by QFT-GIT [17]. The Korean government began to provide systematic LTBI diagnosis for about 1.2 million individuals in high risk groups, including HCWs, social welfare facility workers, 
Table 4. Determinants associated with acceptance rate for latent tuberculosis infection treatment: univariate analysis and multivariate analysis.

\begin{tabular}{|c|c|c|c|c|c|}
\hline & \multirow{2}{*}{$\begin{array}{c}\text { LTBI } \\
\mathrm{N}=235\end{array}$} & \multirow{2}{*}{$\begin{array}{c}\text { Acceptance of } \\
\text { treatment for } \\
\text { LTBI }(\%)\end{array}$} & \multirow{2}{*}{$\begin{array}{c}P \text {-value } \\
\text { (univariate } \\
\text { analysis) }\end{array}$} & \multicolumn{2}{|c|}{ Multivariate analysis } \\
\hline & & & & $\begin{array}{c}\text { Odds ratio } \\
(95 \% \mathrm{CI})\end{array}$ & $P$-value \\
\hline \multicolumn{6}{|l|}{ Heath care facility } \\
\hline tertiary hospital (hospital A) & 149 & $81(54.4)$ & 0.01 & $0.52(0.27-1.00)$ & 0.05 \\
\hline secondary hospital (hospital B) & 86 & $61(70.9)$ & & & \\
\hline \multicolumn{6}{|l|}{ Age range, years } \\
\hline $20-29$ & 47 & $38(80.9)$ & $<0.001$ & Reference & \\
\hline $30-39$ & 57 & $30(52.6)$ & & $3.35(1.31-8.54)$ & 0.01 \\
\hline $40-49$ & 69 & $47(68.1)$ & & $1.65(0.63-4.32)$ & 0.31 \\
\hline$\geq 50$ & 62 & $27(43.5)$ & & $3.88(1.53-9.81)$ & $<0.001$ \\
\hline \multicolumn{6}{|l|}{ Sex } \\
\hline Female & 150 & $99(66.0)$ & 0.02 & $0.70(0.32-1.51)$ & 0.36 \\
\hline Male & 85 & $43(50.6)$ & & & \\
\hline \multicolumn{6}{|l|}{ Years working in hospitals } \\
\hline$<11$ & 102 & $72(70.6)$ & 0.02 & Reference & \\
\hline $11-20$ & 40 & $24(60.0)$ & & $0.56(0.21-1.47)$ & 0.24 \\
\hline $21-30$ & 61 & $28(45.9)$ & & $0.32(0.09-1.07)$ & 0.06 \\
\hline$>30$ & 32 & $18(56.3)$ & & $0.79(0.17-3.64)$ & 0.76 \\
\hline \multicolumn{6}{|l|}{ Profession } \\
\hline Doctors & 41 & $22(53.7)$ & $<0.001$ & Reference & \\
\hline Nurses & 110 & $83(75.5)$ & & $2.24(1.01-4.94)$ & 0.05 \\
\hline Nursing assistants, Paramedics & 34 & $17(50.0)$ & & $0.96(0.37-2.49)$ & 0.92 \\
\hline Lab workers & 15 & $6(40.0)$ & & $0.48(0.13-1.77)$ & 0.27 \\
\hline Others, including clerks & 35 & $14(40.0)$ & & $0.54(0.20-1.41)$ & 0.21 \\
\hline \multicolumn{6}{|l|}{ Risk classification } \\
\hline Group 1 & 51 & $35(68.6)$ & 0.04 & Reference & \\
\hline Group 2 & 43 & $29(67.4)$ & & $0.88(0.32-2.42)$ & 0.81 \\
\hline Group 3 & 104 & $63(60.6)$ & & $0.57(0.25-1.32)$ & 0.19 \\
\hline Group 4 & 37 & $15(40.5)$ & & $0.53(0.12-2.26)$ & 0.39 \\
\hline
\end{tabular}

prisoners, military personnel, first-grade high school students, and kindergarten teachers in 2017. Of those, 140,000 people (11.6\%) tested positive for LTBI. A total of 202,668 HCWs underwent screening for LTBI and showed a positive rate of $17.5 \%$. The rate of LTBI in HCWs was higher than that of non HCWs [18]. And the rate of LTBI in HCWs was nearly consistent with the results of this study. In our study, age, gender, years working in hospitals and occupations were significant risk factors for LTBI in univariate analysis. In terms of occupa- 
tional classification, the rate of LTBI in lab workers was highest. In several Korean studies carried out before, laboratory workers were found to be vulnerable to TB infection through exposure to contagious specimens from patients [19]. Increased age was the only significant risk factor identified in this study. Many other studies also reported increased age to be a factor influencing the increase in LTBI [20] [21] [22]. In the LTBI screening conducted by the government in 2017 mentioned above, the LTBI rate similarly increased with age. Though HCWs were classified into four categories by the degree of risk, they did not show any significant difference in the rate of LTBI.

In this study, $60.43 \%$ of HCWs diagnosed with LTBI began to receive treatment, and $93.7 \%$ completed the treatment. In terms of age, the treatment acceptance rate was highest in the youngest age group. The acceptance rate of LTBI treatment was higher in HCWs at the secondary hospital, and in females. The shorter the duration of working life, the higher the treatment acceptance rate. Moreover, in terms of risk classification, the acceptance rate of the HCWs of group 1 was the highest. Multivariate analysis revealed no independently associated factors. Considering that treatment for LTBI was not obligatory, the perception by HCWs of LTBI may influence treatment decisions. In a ten-year study conducted in a medical center in the US on HCW acceptance rates for LTBI treatment, the overall acceptance rate was $39 \%$, ranging from $31 \%$ to $62 \%$ [23]. According to the results from other two tertiary hospitals in Korea based on the Korean Manual for TB Management in Medical institutions updated in 2016, the positive rates of LTBI were $18.8 \%$ and $20.8 \%$ respectively, similar to the result of this study. The acceptance rate for treatment was higher among women, in the younger age group, and in group 1 and 2 among four groups classified by the degree of risk like our study [24] [25]. Our study had several limitations. First, this was a retrospective review and there is lack of information about the reasons for declining treatment for LTBI. Second, not all HCWs participated in the study, that would affect the final outcome. Additionally, there was no baseline data of LTBI for all HCWs, and it was difficult to confirm whether latent TB was infected by patients.

\section{Conclusion}

In conclusion, for HCWs with a high proportion of TB infection, LTBI tests should be recommended. According to risk classification among HCWs, they did not show any significant difference. Only age was independent risk factor for LTBI. As a result, it is necessary to conduct screening of all HCWs, regardless of risk classification. There is a need for additional studies to be performed taking into consideration both the side effects and the effects of the treatment of LTBI in HCWs. It is necessary to investigate the need for treatment of LTBI by the risk classification among HCWs, considering the impact on patients in hospitals at the time of TB onset in the HCWs. Through policies based on this, we will be able to contribute to reducing TB infection in HCWs over the long term and lo- 
wering the burden of TB throughout the country.

\section{Acknowledgements}

We thank the study participants, who gave valuable information.

\section{Conflicts of Interest}

The authors declare no conflicts of interest regarding the publication of this paper.

\section{References}

[1] World Health Organization (2016) Global Tuberculosis Report 2016. World Health Organization, Geneva.

[2] Korea National Tuberculosis Association (2017) 7th Korea National Health and Nutrition Examination Survey 1st Year (2016) Tuberculin Survey Support and Quality Control. Korea Centers for Disease Control \& Prevention. http://www.ndsl.kr/ndsl/search/detail/report/reportSearchResultDetail.do?cn=TRK O201700005159 https://doi.org/10.21742/apjpc.2017.1.2.02

[3] World Health Organization (2011) WHO Report 2011: Global Tuberculosis Control. World Health Organization, Geneva.

[4] World Health Organization (2015) Guidelines on the Management of Latent Tuberculosis Infection. World Health Organization, Geneva.

[5] Cohn, D.L., O’Brien, R.J., Geiter, L.J., Rockville, M., Gordin, F.M., Hershfield, E., Horsburgh Jr., C.R., Jereb, J.A., Jordan, T.J. and Kaplan, J.E. (2000) Targeted Tuberculin Testing and Treatment of Latent Tuberculosis Infection. American Journal of Respiratory and Critical Care Medicine, 161, S221-S247. https://doi.org/10.1164/ajrccm.161.supplement_3.ats600

[6] Menzies, D., Pai, M. and Comstock, G. (2007) Meta-Analysis: New Tests for the Diagnosis of Latent Tuberculosis Infection: Areas of Uncertainty and Recommendations for Research. Annals of Internal Medicine, 146, 340-354. https://doi.org/10.7326/0003-4819-146-5-200703060-00006

[7] Alonso-Echanove, J., Granich, R.M., Laszlo, A., Chu, G., Borja, N., Blas, R., Olortegui, A., Binkin, N.J. and Jarvis, W.R. (2001) Occupational Transmission of $\mathrm{Myco}$ bacterium tuberculosis to Health Care Workers in a University Hospital in Lima, Peru. Clinical Infectious Diseases, 33, 589-596. https://doi.org/10.1086/321892

[8] Kantor, H.S., Poblete, R. and Pusateri, S.L. (1988) Nosocomial Transmission of Tuberculosis from Unsuspected Disease. The American Journal of Medicine, 84, 833-838. https://doi.org/10.1016/0002-9343(88)90060-5

[9] World Health Organization (2009) Global Tuberculosis Control 2009: Epidemiology, Strategy, Financing. World Health Organization, Geneva.

[10] Gershon, A.S., McGeer, A., Bayoumi, A.M., Raboud, J. and Yang, J. (2004) Health Care Workers and the Initiation of Treatment for Latent Tuberculosis Infection. Clinical Infectious Diseases, 39, 667-672. https://doi.org/10.1086/422995

[11] Gerberding, J.L., Snider, D.E., Popovic, T., Solomon, S.L., Bernhardt, J.M., Parker, M., Lindegren, M.L., Hewitt, S.M., Rutledge, T.F., McGee, P., Holland, B.J., Cupell, L.G., LaPete, M.A. and Haver, E.R. (1994) Guidelines for Preventing the Transmission of Mycobacterium tuberculosis in Health-Care Facilities, 1994. Centers for 
Disease Control and Prevention. MMWR Recommendations and Reports, 43, $1-132$.

[12] Jensen, P.A., Lambert, L.A., Iademarco, M.F. and Ridzon, R. (2005) Guidelines for Preventing the Transmission of Mycobacterium tuberculosis in Health-Care Settings, 2005. MMWR Recommendations and Reports, 54, 1-141.

[13] Tissot, F., Zanetti, G., Francioli, P., Zellweger, J.P. and Zysset, F. (2005) Influence of Bacille Calmette-Guerin Vaccination on Size of Tuberculin Skin Test Reaction: To What Size? Clinical Infectious Diseases, 40, 211-217. https://doi.org/10.1086/426434

[14] Trajman, A., Steffen, R.E. and Menzies, D. (2013) Interferon-Gamma Release Assays versus Tuberculin Skin Testing for the Diagnosis of Latent Tuberculosis Infection: An Overview of the Evidence. Pulmonary Medicine, 2013, Article ID: 601737. https://doi.org/10.1155/2013/601737

[15] Korea Centers for Disease Control \& Prevention (2016) The Korean Manual for Tuberculosis Management in Medical Institutions: Korea Centers for Disease Control \& Prevention.

http://www.cdc.go.kr/CDC/cms/cmsFileSeDownload.jsp?fid=20\&cid=128374\&field Name=attach $1 \&$ index $=1 \& f k=14 d 1 c c 4357174881 b d 1 b 47371372102 b 87 d 196 b d 97336$ 29329906296e9ef9d8f

[16] Lee, K., Han, M.K., Choi, H.R., Choi, C.M., Oh, Y.M., Lee, S.D., Kim, W.S., Kim, D.S., Woo, J.H. and Shim, T.S. (2009) Annual Incidence of Latent Tuberculosis Infection among Newly Employed Nurses at a Tertiary Care University Hospital. Infection Control \& Hospital Epidemiology, 30, 1218-1222. https://doi.org/10.1086/648082

[17] Lee, J.K., et al. (2010) Screening for Latent Tuberculosis Infection in South Korean Healthcare Workers Using a Tuberculin Skin Test and Whole Blood Interferon-Gamma Assay. Scandinavian Journal of Infectious Diseases, 42, 672-678. https://doi.org/10.3109/00365548.2010.485575

[18] Cho, K.S., Park, W.S., Jeong, H.R., Kim, M.J., Park, S.J., Park, A.Y., Park, G.R., Division of TB HIV Control and Center for Disease Prevention (2017) Prevalence of Latent Tuberculosis Infection at Congregated Settings in the Republic of Korea. Korea Centers for Disease Control \& Prevention. http://www.cdc.go.kr/CDC/mobile/info/CdcKrInfo0301.jsp?menuIds=HOME001MNU1154-MNU0005-MNU0037-MNU1380\&q_type $=$ \&year $=2018 \&$ cid $=79236 \& \mathrm{pa}$ geNum

[19] Moon, H.W., Kim, H., Hur, M., Yun, Y.M. and Lee, A. (2011) Latent Tuberculosis Infection Screening for Laboratory Personnel Using Interferon-Gamma Release Assay and Tuberculin Skin Test in Korea: An Intermediate Incidence Setting. Journal of Clinical Laboratory Analysis, 25, 382-388. https://doi.org/10.1002/jcla.20479

[20] Jo, K.W., Hong, Y., Park, J.S., Bae, I.G., Eom, J.S., Lee, S.R., Cho, O.H., Choo, E.J., Heo, J.Y., Woo, J.H. and Shim, T.S. (2013) Prevalence of Latent Tuberculosis Infection among Health Care Workers in South Korea: A Multicenter Study. Tuberculosis and Respiratory Diseases (SeouI), 75, 18-24. https://doi.org/10.4046/trd.2013.75.1.18

[21] Mirtskhulava, V., Kempker, R., Shields, K.L., Leonard, M.K., Tsertsvadze, T., del Rio, C., Salakaia, A. and Blumberg, H.M. (2008) Prevalence and Risk Factors for Latent Tuberculosis Infection among Health Care Workers in Georgia. International Journal of Tuberculosis and Lung Disease, 12, 513-519.

[22] Pai, M., Gokhale, K., Joshi, R., Dogra, S., Kalantri, S., Mendiratta, D.K., Narang, P., Daley, C.L., Granich, R.M., Mazurek, G.H., Reingold, A.L., Riley, L.W. and Colford, 
J.M. (2005) Mycobacterium tuberculosis Infection in Health Care Workers in Rural India: Comparison of a Whole-Blood Interferon Gamma Assay with Tuberculin Skin Testing. JAMA, 293, 2746-2755. https://doi.org/10.1001/jama.293.22.2746

[23] Arguello Perez, E., Seo, S.K., Schneider, W.J., Eisenstein, C. and Brown, A.E. (2017) Management of Latent Tuberculosis Infection among Healthcare Workers: 10-Year Experience at a Single Center. Clinical Infectious Diseases, 65, 2105-2111. https://doi.org/10.1093/cid/cix725

[24] Kim, D.M., Kim, Y.J., Kim, J.W., Lee, J.Y. and Lee, D.G. (2018) Treatment Acceptance Rate of Health Care Workers Based on Interferon Gamma Secretion Result. KOSHIC Annual Meeting \& EACIC, 24 May 2018.

[25] Jung, P.N., Hong, M.H., Kim, Y.H., Kim, G.Y., Yim, H.J., Kim, J.Y. and Huh, J.A. (2018) Prevalence and Management of Latent Tuberculosis Infection of Health Care Workers. KOSHIC Annual Meeting \& EACIC, 24 May 2018. 